\title{
Соловьёва Ж.В., Запорожская-Абрамова Е.С. \\ Глубокое фторирование как метод неинвазивного лечения кариеса эмали в стадии «белого пятна»
}

ФГБОУ ВО КубГМУ Минздрава России (Россия, Краснодар)

doi: 10.18411/trnio-10-2021-99

\section{Аннотация}

Данная статья посвящена оценке эффективности глубокого фторирования в лечении кариеса эмали в стадии «белого пятна» на основании результатов лазерной флюоресценции и витального окрашивания.

Ключевые слова: глубокое фторирование, лечение, кариес эмали в стадии белого пятна, лазерная флюоресценция, витальное окрашивание, реминерализация эмали.

\section{Abstract}

This article is devoted to assessing the effectiveness of deep fluoridation in the treatment of enamel caries in the "white spot" stage based on the results of laser fluorescence and vital staining.

Keywords: deep fluoridation, treatment, caries in the stage of white spot, laser fluorescence, vital staining, enamel remineralization.

Несмотря на современные достижения в современной стоматологии, распространенность кариеса остается, по-прежнему, высокой [1]. Установлено, что основой формирования кариозного очага является преобладание процесса деминерализации, в результате чего происходит убыль ионов $\mathrm{Ca} 2+$ и $\mathrm{PO} 43$ - из кристаллической структуры эмали. Кариес эмали в стадии «белого пятна» - это начальная стадия кариозного процесса, при которой возможно предупредить прогрессирование патологического процесса. Для восстановления минерального баланса в кристаллической решетке эмали с целью профилактики и лечения начального кариеса применяются различные активные формы фторидов $[1,2,3,4]$. Механизм действия фтора обусловлен формированием на поверхности эмали глобул фторида кальция, так называемого депо фтора, который способствует реминерализации, увеличивает скорость реакций минералообразования, подавляет активность микроорганизмов. Результатом применения фторид-ионов является образование более прочных кристаллов фторапатита $[1,2]$. Помимо применения различных активных форм фторида широкое распространение получило глубокое фторирование, предложенное профессором А. Кнаппвост. В результате химической реакции при взаимодействии компонентов образуется фторсиликатный комплекс, который, спонтанно распадаясь, формирует нанокристаллы фтористого кальция, магния, меди и полимеризованной кремниевой кислоты. Образованные кристаллы располагаются на поверхности и в глубине пор эмали в тиксотропном геле кремниевой кислоты, обеспечивают пролонгированное выделение ионов фтора (от полугода до 2 лет) в концентрации, достаточной для реминерализации эмали $[1,2,4]$.

Цель исследования: оценка эффективности метода глубокого фторирования в лечении кариеса эмали в стадии «белого пятна».

Материал и методы. Исследование проводили на базе Клиники ФГБОУ ВО КубГМУ Минздрава России. Всего обследовано 65 волонтеров в возрасте 18-28 лет с диагнозом кариес эмали в стадии «белого пятна» с различным уровнем гигиены полости рта без сопутствующей соматической патологии. Добровольцы были проинформированы о предстоящих лечебно-профилактических мероприятиях и дали на них свое согласие.

На первом этапе исследования проводили оценку гигиенического состояния полости рта с помощью индекса OHI-S (I.G.Green и I.R.Vermillion, 1964). В зависимости от показателей индекса OHI-S были сформированы две группы пациентов: 1 группа (32 человек - 81 зуба с диагнозом кариес эмали в стадии «белого пятна») с хорошим и 
удовлетворительным уровнем гигиены полости рта, индекс OHI-S составляет 0-1,67; 2 группа (33 человек - 83 зубов с диагнозом кариес эмали в стадии «белого пятна»), индекс OHI-S варьирует от 1,7 до 3 баллов (уровень гигиены неудовлетворительный и плохой). Всем участникам проводили профессиональную гигиену полости рта ультразвуковым и воздушноабразивным способами, даны рекомендации по средствам гигиены. Для ежедневного применения пациентам рекомендовали использование зубной пасты без фтора. Оценку эффективности глубокого фторирования средством «ФторЛюкс», (ТехноДент) в лечении кариеса эмали в стадии «белого пятна» проводили на основании результатов лазерной флуоресценции аппаратом «DiagnoDent Pen» (KaVo) и витального окрашивания 2\% раствором метиленового синего [1, 2, 3,4].

Мониторинг клинических показателей проводили в следующие сроки: до начала исследования, через три, шесть, двенадцать месяцев. Всем волонтерам проведено четыре процедуры глубокого фторирования с кратностью через семь дней. Для оценки полученных результатов были использованы пакеты компьютерных программ для определения параметров непараметрической статистики (Excel 7.0, StatSoft Statistica 6.0).

Полученные результаты лазерной флуоресценции и витального окрашивания в динамике до и после лечения пациентов с диагнозом кариес эмали в стадии «белого пятна» методом глубокого фторирования приведены в таблице 1 и 2.

Таблица 1

Результаты лазерно-флуоресцентного диагностики в динамике лечения пациентов методом глубокого фторирования

\begin{tabular}{|c|c|c|}
\hline \multicolumn{3}{|c|}{$\begin{array}{c}\text { Показатель лазерно-флуоресиентного метода } \\
\text { (в единицах измерения аппарата «DiagnoDent Pen») }\end{array}$} \\
\hline \multirow{2}{*}{$\begin{array}{c}\text { Сроки } \\
\text { наблюдения }\end{array}$} & \multicolumn{2}{|c|}{ Глубокое фторирование } \\
\hline & I группа (уд. гиг) $n=81$ & II группа (неуд. гиг) $n=83$ \\
\hline \multirow{2}{*}{ До лечения } & $21,78 \pm 1,57$ & $21,95 \pm 1,76$ \\
\hline & \multicolumn{2}{|c|}{$p 0>0,05$} \\
\hline \multirow{3}{*}{$\begin{array}{l}\text { Через } 3 \\
\text { месяца }\end{array}$} & $11,15 \pm 1,037$ & $16,54 \pm 1,24$ \\
\hline & $p 1<0,001$ & $p 1<0,001$ \\
\hline & \multicolumn{2}{|c|}{$p 4<0,001$} \\
\hline \multirow{3}{*}{$\begin{array}{c}\text { Через } 6 \\
\text { месячев }\end{array}$} & $7,39 \pm 1,03$ & $13,55 \pm 0,81$ \\
\hline & $\begin{array}{l}p 1<0,001 \\
p 2<0,01\end{array}$ & $\begin{array}{l}p 1<0,001 \\
p 2<0,01\end{array}$ \\
\hline & \multicolumn{2}{|c|}{$p 5<0,001$} \\
\hline \multirow{3}{*}{$\begin{array}{l}\text { Через } 12 \\
\text { месяиев }\end{array}$} & $4,19 \pm 0,49$ & $10,61 \pm 0,58$ \\
\hline & $\begin{array}{l}p 1<0,001 \\
p 3<0,001\end{array}$ & $\begin{array}{l}p 1<0,001 \\
p 3<0,01\end{array}$ \\
\hline & \multicolumn{2}{|c|}{$p 6<0,001$} \\
\hline
\end{tabular}

Таблица 2

Результаты витального окрашивания в динамике лечения пациентов методом глубокого фторирования

\begin{tabular}{|c|c|c|}
\hline \multicolumn{3}{|c|}{$\begin{array}{c}\text { Показатель витального окрашивания } \\
\text { кариеса в стадии «белого пятна» }\end{array}$} \\
\hline \multirow{2}{*}{$\begin{array}{c}\text { Сроки } \\
\text { наблюдения }\end{array}$} & \multicolumn{2}{|c|}{ Глубокое фторирование } \\
\hline & $\begin{array}{c}\text { I груnпа (yd. гиг) } \\
n=81\end{array}$ & II группа (неуд.гиг) $n=83$ \\
\hline \multirow{2}{*}{ До лечения } & $7,01 \pm 0,67$ & $7,23 \pm 0,71$ \\
\hline & \multicolumn{2}{|c|}{$p 0>0,05$} \\
\hline \multirow{3}{*}{$\begin{array}{l}\text { Через } 3 \\
\text { месячуа }\end{array}$} & $3,71 \pm 0,49$ & $5,54 \pm 0,53$ \\
\hline & $p 1<0,001$ & $p 1<0,01$ \\
\hline & \multicolumn{2}{|c|}{$p 4<0,05$} \\
\hline
\end{tabular}




\begin{tabular}{|c|c|c|}
\hline \multirow{3}{*}{\begin{tabular}{c|c|} 
Через 6 \\
месямев
\end{tabular}} & $2,01 \pm 0,51$ & $3,99 \pm 0,69$ \\
\cline { 2 - 3 } & $p 1<0,001$ & $p 1<0,01$ \\
& $p 2<0,001$ & $p 2<0,05$ \\
\hline \multirow{3}{*}{ Через 12 } & $0,95 \pm 0,25$ & $p 5<0,005$ \\
\cline { 2 - 3 } месячев & $p 1<0,001$ & $3,19 \pm 0,51$ \\
\cline { 2 - 3 } & $p 3<0,01$ & $p 1<0,01$ \\
& \multicolumn{2}{|c|}{$p 6<0,001$} \\
\cline { 2 - 3 }
\end{tabular}

Примечание: р0 - достоверность различий по сравнению с данными второй группь до лечения; p1 - достоверность различий в период 3, 6, 12 месящев лечения по сравнению с показателями до лечения; р2- достоверность различий по сравнению с данными в период лечения через 3 месяца; р3- достоверность различий по сравнению с данными в период лечения через 6 месяиев; 44 - достоверность различий между первой и второй группами на данном наблюдения; р5 - достоверность различий между первой и второй группами на данном наблюдения; р6 - достоверность различий между первой и второй группами на данном наблюдения.

Результаты и обсуждение. У всех участников исследования первой и второй групп до лечения отмечали окрашивание очагов деминерализации эмали в синий цвет разной степени интенсивности. В первой группе у пациентов с удовлетворительным уровнем гигиены полости рта наблюдали выраженное и динамичное снижение интенсивности окрашивания. Во второй группе происходило плавное и не столь выраженное уменьшение интенсивности окрашивания. В первой группе в 91 \% случаев отмечали полное исчезновение окрашивания очагов поражения эмали. Во второй группе к концу срока динамического наблюдения окрашивание пятен сохранялось.

Показатели лазерной флуоресценции эмали аппаратом «DiagnoDent Pen» до лечения составляли от 18 до 25 единиц. Через 3 месяца в первой группе после проведенного лечения отмечали снижение показателей до нормы $(11,15 \pm 1,037, \mathrm{p} 1<0,001)$. В течение последующего срока наблюдения происходило дальнейшее плавное снижение показателей лазерной флуоресценции. В первой подгруппе волонтеров прогрессирование кариозного процесса не было зафиксировано. Во второй группе волонтеров отмечали медленно снижение показателя лазерной флуоресценции в течение всего срока динамического наблюдения, достигнув к его завершению значений верхней границы нормы: $10,61 \pm 0,58, \mathrm{p} 1<0,001$. При этом присутствует риск прогрессирования в начальный кариес при несоблюдении пациентом индивидуальной гигиены полости рта.

\section{Заключение}

Таким образом, методика глубокого фторирования в лечении кариеса эмали в стадии «белого пятна» является статистически значимой и эффективной, препятствует дальнейшему прогрессированию патологического процесса, способствует реминерализации эмали, обеспечивает стойкий клинический эффект. Прогноз лечения: положительный при выполнении пациентами всех рекомендаций по гигиене полости рта.

$$
* * *
$$

1. Соловьёва Ж.В., Запорожская-Абрамова Е.С., Адамчик А.А., Косырева Т.Ф., Шкиря Т.В. Повышение эффективности вторичной профилактики кариеса у женщин во время беременности // Вестник научных конференций. - 2020. - Т. 18. - № 3. - С. 4-9.

2. Соловьёва Ж.В., Адамчик А.А. Эффективность применения глубокого фторирования в профилактике кариеса // Кубанский научный медицинский вестник. - 2018. - Т. 25. - № 2. - С. 135-139.

3. Mohd Said S.N.B., Ekambaram M., Yiu C.K.Y. Effect of different fluoride varnishes on remineralization of artificial enamel carious lesions // International Journal of Paediatric Dentistry. - 2017. - Vol.27, N3. - P.163-173.

4. Solovyeva Zh.V., Zaporozhskaya-Abramova E., Adamchik A.A., Gushchin A., Risovanny S., Manukyan I.A. Comparative evaluation of the clinical efficacy of modern remineralizing drugs in the treatment of enamel caries (focal demineralization) // Georgian Medical News. - 2021. - № 1 (310). - P.39-44. 